\title{
A Sociology of Translation: From Text World to Life World*
}

\author{
Qingguang Wei \\ Foreign Languages College, Southwest University for Nationalities, Chengdu, China
}

\begin{abstract}
A sociology of translation is not a pure theoretical research nor a logical deduction, but an applied research facing the life world. A sociology of translation calls for new subject, methodology and concepts to comply with it, so that it can surpass the text world. A sociology of translation centers on the social nature of translation, aiming at promoting reciprocity between translation and society.
\end{abstract}

Index Terms—a sociology of translation, social nature, text world, life world

\section{INTRODUCTION}

In recent years, "a sociology of translation" has emerged in the West. Some scholars began to view "translation as a social practice" and incorporate the idea into the framework of "a sociology of translation". Although they have in real sense set a step toward a new research paradigm in translation studies, they have not got a unanimous understanding of the notion of "a sociology of translation". What is its exclusive subject? What methodology should be adopted in this field? What is the research goal in this regard? In this paper, we will make a general survey within the present framework of "a sociology of translation", and try to answer these questions, with the purpose of bringing forth a new research paradigm beyond linguistic approach and cultural approach in translation studies.

\section{A SOCiOlogy of TransLation IN THE West}

In May 2005, a translation symposium was held in University of Graz, Austria, with the theme "translation and interpretation as a social practice". After the meeting, Wolf and Fukari collected the papers contributed and had them printed with the book title Constructing a Sociology of Translation in 2007 by John Benjamins Publishing Company. The publication symbols the emergence of "a sociology of translation".

Constructing a Sociology of Translation centers on the subject of "translation as a social practice". In Part I (The debate on the translator's position in an emerging sociology), Erich Prunč (2007) investigated the historical, social and cultural reasons for the discrepancy between the rather marginal status of the translator. The study is characteristic of social constructivism. In the paper "Translation, Irritation and Resonance", Theo Hermans (2007), drawing upon Luhmann's social system theory, viewed translation as a social system and held that translation contributes to society's construction of reality.

In Part II (Bourdieu's influence in conceptualizing a sociology of translation), Gouanvic (2007) discussed the application of Bourdieu's "habitus", "field" and "illusion" to translation studies and analyzed the habitus of three agents operating in the translation of American literature in France. Adopting Bourdieu's field theory, Johan Heilbron and Gisèle Sapiro (2007) discussed the power relations between language groups and the international hierarchy of languages. Wolf (2007A) argued that Bourdieu's theory of symbolic goods was not sufficient for the conceptualization of a "mediation space" and tried to employ Homi Bhabha's "Third Space" to develop it.

In Part III (Mapping the field: Issues of method and translation practice), Mirella Agorni (2007) used the concept of localism to mediate between systems and individuals, exploring the possibility of developing a model which could bring together the socio-cultural and the individual aspects of translation. Buzelin (2007), inspired by Bruno Latour's actor-network theory, proposed to focus on the production end of translation activities. Andrew Chesterman (2007) argued that a sociological approach in translation studies centered on translation quality and united the notions of causality, translation practice, discourse and habitus, translation norm, brief, and strategy.

In Part IV (Constructing a sociology of translation studies: Overview and perspectives), Daniel Simeoni (2007) conducted a review of translation studies in the fields of sociology and history, elaborating why it took translation scholars so long to pay attention to the "social" in translation. Yves Gambier (2007) outlined the prerequisites for the creation of socio-translation studies: self-analysis of scholars, a historiography of the field, and an analysis of institutions and publications which shape and identify the discipline.

A sociology of translation has added a dimension to translation studies. However, in the brief survey, we find that although a sociology of translation in the West views translation as a social practice, scholars did not study translation

\footnotetext{
* This paper is supported by Philosophical and Social Science Planning Program of Sichuan Province (No. SC13WY09) and the Fundamental Research Funds for the Central Universities of Southwest University for Nationalities (No. 13SZYBS20).
} 
activities against the social contexts. They merely adopt some sociological research methods or theoretical framework to study translation activities. Wolf also remarked in Constructing a Sociology of Translation: "A more important purpose of this volume, however, is to improve the conjunction of translation studies and sociology and thus foster the development of a methodological basis." (2007B, p. 1) Since translation is acknowledged as a social practice, we should investigate translation activities against the broad social context and interpret the social conditions behind translation activities.

Scholars in the West mainly adopt theories from sociologists like Bourdieu, Luhmann and Latour in a sociology of translation. Judging from the developmental context of sociology, these sociologists fall into the category of social constructionism. Social constructionism is "an academically anti-oppotimistic trend" (Yan Zhigang, 2006, p. 24), which assumes the presupposition of phenomenology. According to social constructionism, the social reality does not represent itself by means of the objective reality but via the interpreted reality. New social realities are continually constructed through the interpretation of social reality. The fundamental assumption of this paradigm is that "reality is socially constructed" (Berger \& Luckmann, 1966, p. 1). In the theory of social constructionism, the social problem does not exist as an objective reality or condition but as a social activity or process. The so-called "reality" is the result of social construction. People's understanding of things varies because of the history, region, situation and different experiences. So, the social reality constructed cannot be judged genuine or not, but rather suitable or not. The research goal is not to control, predict or transform the objective reality, but to interpret and construct the reality.

The research conclusions of social constructionism are created, so they are doomed to be local. In terms of research methods, there are also some problems. The concepts of translation field proposed by Gouanvic and translation as a social system put forward by Hermans both isolate translation from social structure. It seems that translation has become a separate entity outside social structure. Although the dualist approach is positive in epistemology and conducive to understanding of the seemingly isolated characteristics of translation, it neglects the fact that the real translation environment and social structure are overlapped and that their connections are complicated. If the two are separated, the nature of translations and social structure will be distorted. What's more, researchers, leaving the temporary logical separation in the study alone, have forgotten to reflect the research conclusion after their study. Once the subsystem has been detached from the whole social system, it has been isolated from the social context. In so doing, we cannot reveal the complicated relation between translation and society. Translation studies cannot be only limited to theoretical discretion, but should enter into real life.

\section{A Sociology OF TRANSLATION IN CHINA}

In recent years, there have emerged some comments on and introductions to a sociology of translation in China. Wu Guangjun reviewed the application of Bourdieu's social practice theory, Luhmann's social system theory and Latour's actor-network theory in a sociology of translation and remarked: "A sociology of translation has expanded the bound of translation studies and at the same time brought a more dialectical thinking mode and more rational research approach. This is a big step forward for translation studies." (Wu Guangjun, 2008, p.79) Li Hongman (2008) made a comment on Constructing a Sociology of Translation edited by Wolf and Fukari, thinking that the book is theoretically insightful. Having compared the notion of "a sociology study of translation" and "socio-translation studies", Wang Hongtao (2011) holds that the a more proper title should go to "socio-translation studies" and that Bourdieu's relationism can be adopted as a guiding principle in exploring mutual influence and reciprocal transformation of various subjective and objective factors in translation. Although Chinese scholars' introduction of a sociology of translation in the West is conducive to widening the vision of Chinese researchers, their study, merely clinging to comments, review, interpretation or advocating, has not gone beyond that of the western scholars. And China's cultural tradition, social institution and translation mechanism are quite different from those of western countries. Even though the theories proposed by western scholars are very effective in interpreting translation events in the West, those theories may put a force upon China's translation reality, thus, ineffective.

In fact, there has emerged a tiny trend in studying the social aspect of translation in China. Professor Lv Jun proposed: "With regard to translation studies, we should give more attention to the study of the social aspect of translation, because in the long past, when doing translation study, people have placed it on a naïve foundation - translation is done in vacuum without any distraction." (2001, p.9) And some translation symposiums in China have also begun to take interest in a sociology of translation. In the symposium of Translation Teaching and Research in the Global Horizon held in October 2010 at Zhejiang Normal University, one of the topics in calling for papers is "such special issues as a sociology of translation and translation ethics". Unfortunately, we did not find any contribution concerning the issue of a sociology of translation at the symposium. Perhaps the research findings in this regard have been premature and were not presented at the symposium.

\section{FROM TEXT WORLD TO LIFE WORLD}

A sociology of translation in the West, though viewing translation as a social practice, has not embedded translation activities in the broad social context. The narrow vision is not conducive to understanding and deeper research of translation activities. The academic circle in China, only confined to simple introduction of and comment on Western 
translation theories in this regard, has not come up with any new understanding or interpretation of translation activities, nor put forth any new perception for translation theories.

The reflection of any event has its own social context. With the development of society and the changing of the times as well as the ever-enriching of cross-cultural communication, translation activities and their relation with the social context have become increasingly complicated. As an indispensible part of the social structure, translation activities have undergone some changes and will continue to change. All these changes require that we should interpret translation activities in a new approach. In other words, if we merely confine our understanding of translation activities to the area of linguistic study, we can hardly have any break through in our understanding of translation activities and we cannot make any improvement in translation studies. Only if we discuss translation activities on a multi level can we have a new understanding of translation.

Targeting the intention that linguists separate language from other activities, Bourdieu pointed out: "I think one cannot fully understand language without placing linguistic practices within the full universe of compossible practice." (Bourdieu \& Wacquant, 1992, p. 149) Wittgenstein (1953) used the term "language-game" to designate forms of language simpler than the entirety of a language itself. And Wittgenstein elaborated further: "Here the term 'language-game' is meant to bring into prominence the fact that the speaking of language is part of an activity, or of a form of life." (ibid, p. 23) In other words, language is inseparable from life.

Language is life. We should study language through the observation of life world. As an activity of language transfer, translation is life as well. Unless we place translation activities into the life world where various social activities co-exist, we cannot investigate and fully understand translation activities. Translation studies should, via the investigation of life world, keep up with the times. The key for a theory to remain alive is to connect the life world for new information. For the same reason, we should break through the framework, concepts and methodology in the text world, and introduce a new research paradigm into translation studies so that our research can enter into the life world from the text world.

Compared with linguistic perspective, a sociology of translation should stay away from the tendency in which translation studies have been trapped within text translation and focuses on the relation between translation and the life world. Latour already pointed out: "If I want to be a scientist and reach objectivity, I have to be able to travel from one frame of reference to the next, from one standpoint to the next. Without those displacements, I would be limited to my own narrow point of view for good." (2005, p. 146) The switch of research perspective requires a new set of concept category and analytical framework to accommodate it.

\section{A. Research Subject: Social Nature of Translation}

Translation activities have never been performed in the "vacuum". From the determination of translation goal, motivation of translators, launching translation task to the admittance of translation products into society, we can deem that as a social operation. Since the goal of translation is to communicate knowledge and culture, translation activities can never be separable from our society.

Translation activities are embedded in society. Translation activities are performed by human beings, who embody some social relations as always. The trajectory and condition of translation activities are determined by the interests of communities, cultural choice, value orientation and power pattern. Translation activities play a bridging and bounding role in promoting social progress, economic growth and cultural communication. In this sense, the social nature is one of the fundamental natures of translation.

However, the social nature of translation has long been neglected. This has much to do with the status of translation studies. First as a sub-discipline of contrastive linguistics, linguistic study has long been prevailing in translation studies. The linguistic approach focuses on text, treating translation as a linear operation. This approach is interested in such concepts as equivalence, naturalness and fluency and in finding regularities to put the meaning in the source language into target language.

With the arrival of "cultural turn" in translation studies in the 1990s, the scope of translation studies has been expanded. On the cultural level, with culture representing the environment of translation, translation studies focus on the transfer of cultural factors between different repertoires or polysystems and on unveiling the inequality behind texts. This approach is interested in ideology, cultural identity, the relation between the center and periphery, power, and ethics. Although in the cultural turn the scope of translation studies has been expanded, with the focus on uncertainty of textual meaning and interperception of cultural factors, the social conditions have been placed aside, and the study on social implicature of translation activities has not got its due recognition.

Due to negligence of the social nature of translation, current translation studies outrun the life world by keeping to the fixed research methods without regard to the problems in real-life translation operation. In this regard, people do not study translation activities according to the real-life requirements, but cling to disciplinary boundary. They do not carry out research in accordance with social needs, but choose the issues in the framework of current research methods. The notion that methods determine subjects has brought about the fact that translation studies stay away from life world and the requirements of social practice.

Translating is not only a cognitive process, but also an open system consisting of cooperation, communication, negotiation, argument, compromise and consensus. In the life world, translation assumes the task of serving society via communication. The internal activity of any event is bound to be restricted or influenced by external conditions. 
Translation is a complex and open activity. If we do not break through the internal bound or surpass the text world, we could not understand the real sense of translation activities.

A translation product, from the choice of the original and translation strategy to the production and release of translation products, is the result of social negotiation and construction. A translation activity in any society or period will reflect the structure or relation in that society or period. Translation activities operate in society, correlating with the life world. In contemporary society, the relation between translation activities and society are becoming increasingly close. The social problems triggered by translation and problems in translation caused by social context and changes are more and more complex. So priority should be given to the social nature of translation.

\section{B. Research Methodology: System Thinking}

Economic globalization has changed people's outlook on life and the world. In the era of economic globalization, nothing is isolated. Everything is embedded in the inter-relationship with others. In observing an activity, we must not take a solitary or partial view. An individual or special event can only be understood properly when correlated with the life world.

By the same token, we cannot solve the problems in translation activities in an isolated way. If the factors in translation activities could not interact properly, the whole translation system might end up with a disaster. Therefore, to solve the problems in translation activities in the life world, we should adopt the methodology of system thinking. "System thinking is a discipline for seeing the wholes. It is a framework for seeing interrelationships rather than things, for seeing patterns of changes rather than static 'snapshots'." (Senge, 1990, p. 68)

From the perspective of system thinking, simple solutions are rarely effective because they only focus on one part, neglecting the interaction with other parts of the whole system. The weakness of partial thinking is that people merely transfer the problem from one place to another without solving it radically. In interpreting the effect of one activity, people tend to examine the factors of the activity, neglecting other factors that are relevant to it. The labels posted by people to the causes and effects of translation activities are often arbitrary, because the effect of one activity is usually random or unexpected. A translation activity is a complicated organic whole, which involves many factors. The functional effect depends on the interaction of the factors in the system and their relation with those outside of the system. In other words, the various problems in translation activities are not isolated but brought about from the irrational social operation in society.

Translation activities are an open system. Operating in society, translation activities involve complicated relations----the results might go against the purposes; the controlling measures might not reach the expected effect. Therefore, to solve problems in translation, we cannot merely explore individual factors. As a social practice, translation activities have some connections with the life world and we must interpret translation activities against these connections. At the same time, facing the future, individuals and the whole society will have to make a variety of options, which will exert influence on the future development. Multi-options will bring about an unstable context for translation system. If we do not take into account of these problems on the whole, the optimization of one link will cause instability to the entire translation system. Therefore, targeting various problems in translation activities, we should reflect and address them systematically.

By adopting system thinking, we can study the systematic characteristics displayed in the indirect effects when the various elements of translation activity surpass the dimension of time and space and interact with one another. Then we will employ an integrated and organic research framework to construct and optimize the operating mechanism for translation activities.

\section{Research Goal: Serving Society}

With the introduction of new research paradigms, translation studies can be expanded and innovated. Holmes has already pointed out: “...translation studies thus has two main objectives: (1) to describe the phenomena of translating and translation(s) as they manifest themselves in the world of our experience, and (2) to establish general principles by means of which these phenomena can be explained and predicted."(2000, p. 176) Because of our different perspectives and perceptions of translation activities, there should have been different perspective levels in translation studies. In order to better understand various translation activities in the life world, it is necessary for us to view translation activities as an organic component of the whole life world and systemically study various translation activities in real life.

A sociology of translation is closely related to the quality of translation products. The findings are of great help for us to understand the interaction between translation and society, as well as for translation to serve society better. A sociology of translation provides a special perspective for us to examine translation activities and their interaction with social context. Through the observation of the interaction, it is helpful for us to discover, describe and explain the complex problems in translation activities with a new insight.

A sociology of translation attaches great importance to the empirical materials in translation activities. By describing and analyzing these materials, we can authentically represent various maps in translation activities. Besides, a sociology of translation aims at addressing problems. And the findings can forecast the possibilities and provide constructive advice and proposals for future translation activities. 


\section{CONCLUSION}

The social nature of translation activities and their role in social development have not received their due recognition. Although efforts have already been made in this regard, they tend to be contingent solutions. Seldom have translation activities been studied from the perspective of the overall social development. The unawareness of the social nature of translation activities has, to a large extent, limited the range and depth of current translation studies, and many problems cannot be resolved within the present text world of translation studies. In order to better understand translation activities and address problems in this regard, we should break through the text world and examine translation problems in the life world. This is the task of a sociology of translation.

\section{REFERENCES}

[1] Agorni, Mirella. (2007). Locating Systems and Individuals in Translation Studies. Wolf and Fukari (eds). Constructing a Sociology of Translation. Amsterdam and Philadelphia: John Benjamins, 123-134.

[2] Berger, P., \& Luckmann, T. (1996). The Social Construction of Reality: A Treatise in the Sociology of Knowledge. Garden City. NY: Doubleday.

[3] Bourdieu, Pierre \& Loïc J. D. Wacquant. (1992). An Invitation to Reflexive Sociology. Chicago: University of Chicago Press.

[4] Buzelin, Hélène. (2007). Translations "in the Making”. Wolf and Fukari (eds). Constructing a Sociology of Translation. Amsterdam and Philadelphia: John Benjamins, 135-170.

[5] Chesterman, Andrew. (2007). Bridge Concepts in Translation Sociology. Wolf and Fukari (eds). Constructing a Sociology of Translation. Amsterdam and Philadelphia: John Benjamins, 171-186.

[6] Gambier, Yves. (2007). Y a-t-il Place Pour une Socio-traductologie?. Wolf and Fukari (eds). Constructing a Sociology of Translation. Amsterdam and Philadelphia: John Benjamins, 205-218.

[7] Gouanvic, Jean-Marc. (2007). Objectivation, Réflexivité et Traduction. Pour une Re-lecture Bourdieusienne de la Traduction. Wolf and Fukari (eds). Constructing a Sociology of Translation. Amsterdam and Philadelphia: John Benjamins, 79-92.

[8] Heilbron, Johan. \& Gisèle Sapiro. (2007). Outline for a sociology of translation. Current issues and future prospects. Wolf and Fukari (eds). Constructing a Sociology of Translation. Amsterdam and Philadelphia: John Benjamins, 93-108.

[9] Hermans, Theo. (2007). Translation, Irritation and Resonance. Wolf and Fukari (eds). Constructing a Sociology of Translation. Amsterdam and Philadelphia: John Benjamins, 57-78.

[10] Holmes, J. (2000). The Nature of Translation Studies. Venuti, L.(ed). The Translation Studies Reader, London and New York: Routledge, 172-185.

[11] Latour, B. (2005). Reassembling the Social: An Introduction to Actor-Network-Theory, New York: Oxford University Press.

[12] Li Hongman. (2008). A Sociological Approach in Translation Studies: Comments on Constructing a Sociology of Translation. Chinese Translators' Journal, (6): 30-33.

[13] Lv Jun. (2001). Reflection on Constructing Translation Studies. Chinese Translators'Journal, (4): 6-9.

[14] Prunč, Erich. (2007). Priests, Princes and Pariahs. Constructing the Professional Field of Translation. Wolf and Fukari (eds). Constructing a Sociology of Translation. Amsterdam and Philadelphia: John Benjamins, 39-56.

[15] Senge, Peter M. (1990). The Fifth Discipline: The Art and Practice of the Learning Organization. New York: Doubleday/Currency.

[16] Simeoni, Daniel. (2007). Between Sociology and History. Method in Context and in Practice. Wolf and Fukari (eds). Constructing a Sociology of Translation. Amsterdam and Philadelphia: John Benjamins, 187-204.

[17] Wang Hongtao. (2011). Constructing Socio-translation Studies: Name and Nature. Chinese Translators'Journal, (1): 14-18.

[18] Wittgenstein, Ludwig. (1953). Philosophical Investigations. Oxford: Blackwell Publishing.

[19] Wolf, Michaela. (2007A). The Location of the "Translation Field": Negotiating Borderlines Between Pierre Bourdieu and Homi Bhabha. Wolf and Fukari (eds). Constructing a Sociology of Translation. Amsterdam and Philadelphia: John Benjamins, $109-122$.

[20] Wolf, Michaela. (2007B). Introduction: The Emergence of a Sociology of Translation. Wolf and Fukari (eds). Constructing a Sociology of Translation. Amsterdam and Philadelphia: John Benjamins, 1-31.

[21] Wu Guangjun. (2008). The Status Quo and Problems in a Sociology of Transtion. Foreign Languages, (1): 75-82.

[22] Yan Zhigang. (2006). Social Constructionism: A New Perspective in Studying Social Problems. Society, (1): 23-35.

Qingguang Wei received his $\mathrm{PhD}$ from East China Normal University, China. He is currently Associate Professor in Foreign Languages College, Southwest University for Nationalities. His academic publications include Course book on Literary Translation, Lexical Gap in Translation, Chinese-English Translation: Techniques, Teaching \& Theoretical Analyses, Practical English-Chinese Translation and a variety of journal articles on translation. 